\title{
Empresas autónomas y grupos de inversión. Las empresas del grupo Morrison en Rosario, Argentina (1890-1930)
}

\author{
Free standing companies and investment groups. \\ The Morrison companies in Rosario, Argentina (1890-1930) \\ NORMA S. LANCIOTTI \\ Universidad Nacional de Rosario y \\ Consejo Nacional de Investigaciones Científicas y Técnicas, Argentina
}

\begin{abstract}
RESUMEN
Con el objetivo de reconsiderar las tesis relativas a la caída de la rentabilidad de las inversiones británicas en Argentina desde la primera posguerra mundial, se analizan las

trayectorias de dos empresas inglesas de servicios públicos que operaron en Rosario

desde el comienzo de sus actividades, a finales del siglo XIX, hasta 1930: la Compañía de Aguas Corrientes del Rosario y la Compañía de

Obras de Salubridad del Rosario. Ambas empresas operaban bajo el control del grupo de inversión Morrison, pero sus trayectorias

fueron divergentes. Previo análisis de la

información contable de las empresas, se evalúa su grado de autonomía y los factores que incidieron en sus ingresos y rentabilidad, en concreto las condiciones de producción y demanda de los servicios de aguas corrientes

y cloacas, la relación con las autoridades según los términos de las concesiones, y las estrategias de gestión frente a las

transformaciones del mercado local y del mercado internacional de capitales.

PALABRAS CLAVE: Empresas de servicios públicos, Grupos británicos de inversión, Rosario, Argentina
\end{abstract}

Códigos JEL: N7, L1, L2, L9

\section{ABSTRACT}

In order to think over the historiographical debate of the decreasing profitability of the British investments in Argentina from the first postwar period onwards, the performance of two English public utility companies in Rosario are analyzed from the beginning of their activities, at the end of the 19th century, up to 1930: The Rosario Waterworks Company and the Rosario City Improvements. The two companies were under control of the same investment group (Morrison), however their performances diverged. Throughout the analysis of the accounting data, we examine the firms' management and the elements that influenced their revenues and profitability: waterworks and sewerage utilities production conditions and demand, the relationship with authorities according to the concession terms, and the managerial strategies in changing domestic and international capital markets.

KEY WORDS: Public Utility Companies, British Investments Groups, Rosario, Argentina

JEL Codes: N7, L1, L2, L9 


\section{Introducción ${ }^{1}$}

$\mathrm{L}$

a historiografía sobre la economía británica entre finales del siglo XIX y principios del XX ha señalado que la estructura del sector empresarial, caracterizada por el predominio del capitalismo familiar, y el desarrollo de inversiones en el exterior en función de las estrategias de grupos de origen mercantil, constituyeron factores clave a la hora de evaluar los comienzos del declive de la economía inglesa y la pérdida de su posición hegemónica en la economía internacional a partir de la I Guerra Mundial2 ${ }^{2}$.

Al respecto, Mira Wilkins afirma que las empresas inglesas en el exterior, especialmente las compañías autónomas (free standing companies) en Estados Unidos, no tuvieron un desempeño económico satisfactorio tras la Gran Guerra, registrando un alto índice de mortalidad. Wilkins atribuye esta situación a fallos en la creación de organizaciones directivas satisfactorias. Por su parte, Geoffrey Jones ha relativizado la debilidad de las estructuras gerenciales en los grupos británicos, identificando competencias específicas fundadas en la información, la reputación y los contactos, y formas de organización flexibles que explicarían la permanencia de las firmas británicas en el exterior después de 1918. Según Jones, la pérdida de competitividad de la industria inglesa y la naturaleza del mercado británico de capitales fueron los factores que ocasionaron problemas en el largo plazo a las empresas que invirtieron en sectores capital-intensivos y de alto riesgo. El incremento del riesgo y la incertidumbre en la economía de entreguerras marcarían la preferencia de los grupos de negocios británicos por operar bajo entornos de negociación antes que de competencia en el mercado ${ }^{3}$.

[Fecha de recepción del original, septiembre de 2006. Versión definitiva, enero de 2007]

1 Este trabajo es parte de una investigación sobre "Políticas de inversión y estrategias económicas de las empresas extranjeras de servicios públicos en Rosario (Argentina), 1890-1952" inscrita en una beca posdoctoral del Consejo Nacional de Investigaciones Científicas y Técnicas, bajo la dirección de María Inés Barbero. Agradezco las valiosas sugerencias de María Inés Barbero y de Andrés Regalsky a una versión preliminar de este trabajo, así como las efectuadas por los evaluadores anónimos de Investigaciones de Historia Económica.

2 Chandler (1996); Pollard (1985); Chapman (1985), y Hannah (1991).

3 Wilkins (1986) y (1988). En principio, Jones afirmaba que las estructuras gerenciales poco sofisticadas y escasamente autónomas de las multinacionales británicas debilitaron su competitividad y rentabilidad en el período de entreguerras (Jones, 1986, p. 109). Posteriormente, reconsideró la cuestión, optando por redefinir a los grupos inversores como grupos de negocios para enfatizar las capacidades directivas de estas organizaciones. La aversión al riesgo se confirma, no obstante, por la permanencia de instituciones financieras orientadas a maximizar el rendimiento de las inversiones en el corto plazo y el aumento de la incertidumbre (Jones, 2000, pp. 158-194 y 338-353). Miller (1998) coincide en que los límites financieros y tecnológicos de la economía británica explican mejor las dificultades de las empresas inglesas en Perú, Chile y Bolivia después de 1914. 
Desde otra perspectiva, los estudios tributarios de la tesis de Desmond C.M. Platt sobre el imperialismo fallido establecen que la escasa capacidad de presión de las empresas británicas, que habían desarrollado grandes inversiones fijas en activos inmovilizados, y la resistencia local al capital extranjero limitaron la rentabilidad de las inversiones en América Latina. En esta línea, Charles Jones afirma que los británicos se desprendieron de las empresas de servicios públicos en Argentina porque el negocio no era rentable, debido a los sucesivos conflictos con las autoridades locales, ante cuyo hostigamiento los grupos de inversión eran vulnerables ${ }^{4}$.

Con el objetivo de reconsiderar las tesis relativas a la caída de la rentabilidad de las inversiones británicas en Argentina tras la I Guerra Mundial, nos proponemos evaluar la trayectoria de las empresas inglesas de servicios públicos que operaban en la ciudad de Rosario desde el comienzo de sus actividades, a finales del siglo XIX, hasta 1930. Específicamente, analizaremos la Compañía de Aguas Corrientes del Rosario (Rosario Waterworks Company) y la Compañía de Obras de Salubridad del Rosario (Rosario City Improvements $)^{5}$. Ambas compañías pertenecían al grupo inversor británico conocido como Morris o Morrison, y compartían el personal gerencial y administrativo; pero sus trayectorias económicas fueron notoriamente diferentes. La Compañía de Aguas Corrientes tuvo ingresos crecientes desde 1896, moderados gastos de explotación y beneficios elevados a partir de 1900. Por el contrario, la evolución de la empresa de cloacas fue muy irregular, no obtuvo beneficios hasta 1907 y los dividendos no alcanzaron el 6 por 100 hasta 1925.

Las divergencias pueden atribuirse a variables asociadas a las condiciones de producción y demanda de los servicios de aguas corrientes y de cloacas, a la relación con las autoridades locales y a los términos de las concesiones, así como a las estrategias de gestión financiera y administrativa desarrolladas frente a las transformaciones del mercado local y a las condiciones del mercado internacional de capitales en el momento de la creación de las empresas ${ }^{6}$. La incidencia de estos factores se evaluará en las trayectorias de las empresas británicas, prestándose especial atención a los mecanismos de coordinación implementados por los directivos del grupo inversor. Tras exponerse brevemente las condiciones generales bajo las cuales se gestionó el sistema de salubridad en Argentina hasta 1930, se examinan las

En la década de 1880, Argentina era el principal receptor de las inversiones británicas en América Latina. La participación inglesa sobre el total de inversiones disminuyó del 84 al 56 por 100 en la de 1890, pero Inglaterra continuaba siendo el principal país inversor en 1913. Regalsky (2002), pp. 84-85.

6 Exceptuando al sector ferroviario, las empresas de servicios públicos han recibido escasa atención en la historiografía argentina. Véanse García Heras (1994); Barbero (1990); Solveira (2005); Lluch y Sánchez (2002), y Regalsky y Salerno (2006). Sobre las empresas inglesas en Rosario hasta 1900, Jones (1973), cap. IV, y Jones, Jones y Greenhill (1977). 
condiciones bajo las cuales operaron las empresas del grupo Morrison y, sobre la base de la información contable publicada, la evolución anual de su capital accionario, ingresos, gastos, utilidades y dividendos ${ }^{7}$. Finalmente, se reinterpretan los resultados en función de las unidades de análisis propuestas, identificando la relación entre las trayectorias de las empresas y las decisiones operativas y financieras del grupo inversor.

\section{La gestión de los servicios de aguas corrientes y cloacas en Argen- tina, 1880-1930}

En la Argentina de finales del siglo XIX, los gobiernos provinciales y municipales cedieron la explotación de las infraestructuras de servicios urbanos a empresas privadas. Los servicios de aguas corrientes y cloacas constituyeron la excepción. Su construcción y explotación fue asumida por el Estado, como consecuencia de la influencia de la prédica higienista ante los efectos de las epidemias de cólera en las ciudades $^{8}$. En Buenos Aires, la construcción de las obras de salubridad fue gestionada por una Comisión Nacional hasta 1887, cuando se arrendó la explotación de las obras a una empresa privada. Esta experiencia duró pocos años. El contrato con la compañía se rescindió en 1891 y la Comisión Especial de las Obras de Salubridad de la Capital se hizo cargo de las obras. En 1896, la comisión pasó a depender del Ministerio de Obras Públicas, asignándosele la función de construir las obras de salubridad en los territorios nacionales y en las capitales provinciales. El gobierno nacional asumió entonces la responsabilidad sobre los servicios en las ciudades de Buenos Aires, Mendoza, Salta, Corrientes y Mar del Plata; y los gobiernos provinciales respectivos en Córdoba y La Plata9 9

7 Los informes de la Comisión Municipal Fiscalizadora de las Compañias Consolidada de Aguas Corrientes del Rosario y Obras de Salubridad de Rosario contienen datos sobre la evolución del capital, ingresos, egresos, utilidades y dividendos de las compañías de aguas corrientes y cloacas desde el inicio de actividades hasta 1933, información que ha sido contrastada con los datos publicados en la "Contestación de la empresa de aguas al informe de la Comisión".

8 En Buenos Aires y Rosario, las obras de salubridad comenzaron a construirse en el siglo XIX; en Córdoba, Mendoza, Salta, Corrientes, La Plata y Mar del Plata, en el XX.

$9 \quad$ Las leyes nacionales 3.727 (1896) y 3.967 (1900) asignaron a la Comisión (Dirección General de Obras de Salubridad desde 1903) el estudio y la construcción de las obras de salubridad en las capitales provinciales, a financiarse con fondos de la Lotería Nacional y partidas presupuestarias de la nación. La legislación complementaria (leyes nacionales 4.158, 4.881 y 4.312) estableció que los gastos de explotación fueran cubiertos por fondos de las loterías provinciales y por los ingresos de explotación. Cuando estos fueran insuficientes, se utilizarían partidas presupuestarias especiales del Poder Ejecutivo Nacional. República Argentina. Obras Sanitarias de la Nación (1935), s/n. 
En 1912, se creó Obras Sanitarias de la Nación, institución autárquica regida por un directorio, que tomó a su cargo la construcción, explotación y conservación de las obras de saneamiento en el país, incrementándose el gasto público en salubridad. Los ingresos de explotación en Buenos Aires cubrían los gastos financieros y la amortización de los bonos, pero la recaudación no cubría los costes operativos en las restantes ciudades; de modo que la instalación del sistema en las capitales provinciales involucró una fuerte inversión estatal en saneamiento que alcanzó poco más de 110 millones de pesos en $1915^{10}$.

Luego del paréntesis impuesto por la I Guerra Mundial, el alcance nacional de la política de saneamiento se plasmó en la ley 10.998 (1919), que dispuso la ampliación del sistema de agua potable a toda población urbana mayor de 3.000 habitantes, la construcción de redes de cloacas para las poblaciones de más de 8.000 y un cambio en el régimen de financiación de las obras. Se reanudó entonces el crecimiento del gasto en salubridad, alcanzando su nivel más elevado entre 1925 y 1930. En 1934, el servicio de agua potable llegaba a las principales ciudades del territorio nacional ${ }^{11}$.

Sólo dos ciudades, Rosario y Bahía Blanca, ninguna de ellas capital provincial, contrataron las obras de salubridad con empresas privadas sin que mediara financiamiento estatal alguno. En Rosario, la propiedad y gestión de los servicios de aguas corrientes y cloacas estuvo en manos de dos compañías del grupo Morrison hasta 1948, cuando fueron transferidas a Obras Sanitarias de la Nación en el marco de la nacionalización de los servicios públicos impulsada por el gobierno argentino.

\section{El grupo Morrison en Argentina}

La entrada del grupo Morrison en Argentina y Uruguay fue producto de la reorientación de los negocios del banquero Charles Morrison, hijo de un poderoso comerciante británico de textiles. Al disminuir la rentabilidad de sus inversiones de cartera en Estados Unidos, Morrison decidió invertir en Argentina, adquiriendo las acciones devaluadas del Banco Mercantil del Río de la Plata en 1875, con el propósito de retornar a los objetivos iniciales de la entidad: la financiación de obras de infraestructura urbana y transportes. Se organizó entonces el consorcio inversor y, entre 1880 y 1881, se crearon dos compañías: Montevideo Waterworks Company, que obtuvo la concesión de aguas corrientes de dicha urbe uruguaya, y River Plate Trust, Loan $\mathcal{E}$

$10 \quad$ Ley de la Nación 8.889 (1912). The Argentine Year's Book, 1912, pp. 179-180; Regalsky y Salerno (2006), pp. 15-16.

11 La ley autorizaba la emisión de títulos para financiar la construcción y disponía que los gastos de explotación y financieros fueran cubiertos con los ingresos corrientes, quedando las obras afectadas como garantía del pago. Estas condiciones rigieron hasta 1934, cuando la ley 12.140 equiparó los regímenes a lo estipulado por las leyes 3.967 y 4.158. República Argentina. Obras Sanitarias de la Nación (1935). Sobre la inversión estatal en obras de salubridad hacia 1914, véase The Argentine Year's Book, 1914-1915, p. 265. 
Agency (RPTLA, Compañía de Mandatos, Préstamos y Agencia del Río de la Plata), conocida como River Plate Trust o Trust Company. Esta última sería la encargada de administrar los negocios del grupo tras la liquidación del Banco Mercantil ${ }^{12}$.

La actividad inicial de River Plate Trust fue el préstamo hipotecario, siendo la primera empresa especializada en este rubro en Argentina. Poco después, comenzó a operar como agente y consultora de las compañías inglesas de la región. La empresa organizaba consorcios aseguradores y de inversión, administraba la emisión de acciones, títulos y obligaciones de las empresas británicas de transporte y servicios en el mercado londinense, y gestionaba la transferencia de activos entre empresas, así como la liquidación o reconstrucción de compañías. Al final de este proceso, una importante cartera de acciones en empresas anglo-sudamericanas era controlada por el grupo inversor liderado por Morrison ${ }^{13}$.

Durante los años ochenta, el grupo invirtió en sociedades financieras e hipotecarias (Mortgage Company or the River Plate, River Plate and General Investment Trust) y compañías de tierras (Argentine Southern Land Company, Argentine Eastern Land Company, Cordoba Land Company, Río Negro Land Company y Santa Fe Land Company). También adquirió acciones de empresas ferroviarias (Central Railway Company, Central Railway of Chubut, Central Cordoba Railway, Cordoba and Rosario Railway Company, East Argentine Railway Company y Entre Ríos Railway Company). En el sector de transporte y servicios públicos, controlaba Montevideo Waterworks, Paraná Waterworks, River Plate Electricity Co., Ensenada Tramway Company y Buenos Aires and Belgrano Tramways, además de las empresas de aguas y cloacas de Rosario ${ }^{14}$.

Las inversiones diversificadas del grupo tenían una administración centralizada en el directorio de River Plate Trust. Su primer presidente, artífice de la expansión del grupo hasta finales del siglo XIX, fue John Morris, abogado de la familia Morrison en Londres, quien sería desplazado por James Anderson (entonces secretario de la compañía) en 1899. Reginald Neild fue el primer director de la compañía en el Río de la Plata y Alfred Cox su gerente en Buenos Aires. Este cargo sería ejercido luego por Francis Chevallier Boutell, un hombre de negocios británico afincado en Argentina que tenía preciados conocimientos de las características del mercado local y contactos con funcionarios del gobierno nacional ${ }^{15}$.

\footnotetext{
Jones (1973) y (1992), pp. 115-134.

Jones (1973), p. 137.

Jones (1973), pp. 97-178.

La formación del personal directivo sobre la base de relaciones interpersonales, el entrecruzamiento de consejeros entre las firmas vinculadas y la captación de capital de inversión externo a las redes familiares eran mecanismos comunes entre los grupos económicos que operaban en los países en desarrollo (Leff, 1978). Según Jones (2000, pp. 195-266), el cruce de directivos y los contratos entre las firmas son consideradas formas alternativas de control de los grupos de negocios sobre las empresas autónomas, que denotarían la flexibilidad a la par que la firmeza de sus estructuras.
} 


\subsection{La Compañía de Aguas Corrientes de Rosario y la Compañía de Obras de Salubri- dad de Rosario}

En la década de 1880, la precaria condición sanitaria de las ciudades argentinas, visible en las elevadas tasas de mortalidad por enfermedades infectocontagiosas, impuso como prioridad la instalación de los servicios primarios de infraestructura. Las epidemias de cólera, viruela y fiebre tifoidea alertaron a las autoridades locales sobre la gravedad del problema, dado el rápido incremento demográfico de la ciudad de Rosario $^{16}$. Así, en 1884 se contrató la construcción del sistema de aguas corrientes con Andrés Mac Innes, quien pronto transfirió la concesión a la River Plate Trust, Loan and Agency Ltd (RPTLA). Al culminar la primera fase de las obras tres años después, esta compañía transfirió la concesión a otra empresa del grupo, Rosario Waterworks Company Limited (Compañía de Aguas Corrientes de Rosario). Bajo similar modalidad, en 1888, se otorgó la concesión para construir y explotar la red de cloacas a Juan Staniforth, en nombre de RPTLA, que la transfirió a Rosario City Improvements Company Ltd (Compañía Progresos del Rosario) pocos meses después ${ }^{17}$.

Las concesiones de aguas corrientes y cloacas otorgadas contenían cláusulas equivalentes. Ambas se extendían por setenta años con garantía de exclusividad. Con relación a los estándares de calidad, se fijaban las características técnicas del sistema, pero no el volumen de agua a evacuar. La extensión de las redes se pautó en función del incremento demográfico, pero esta condición fue renegociada posteriormente bajo los términos solicitados por la empresa. Las tarifas máximas se fijaron en pesos oro y no se incluyeron restricciones asociadas a límites máximos de utilidades o dividendos. Además, se otorgaron amplias exenciones impositivas durante los primeros veinte años de concesión ${ }^{18}$.

Exceptuando la fijación de los precios en pesos oro y la ausencia de cláusulas de control tarifario, los términos concordaban con la tipología general de las concesiones a empresas de salubridad en las fases iniciales de prestación del servicio. Ciertamente, las concesiones no fijaban barreras legales de entrada en otras latitudes; no obstante, los altos costes y la baja calidad del servicio resultante de la dupli-

16 Rosario tenía 50.914 habitantes en 1887, 222.592 en 1914 y 480.936 en 1930.

17 El capital inicial de la empresa de aguas era de 105.000 libras en acciones ordinarias y 139.100 en acciones preferentes. El de la empresa de cloacas era de 350.000 libras en acciones (50 por 100 ordinarias y 50 por 100 preferentes). Desde 1897, esta última se denominó Compañía de Obras de Salubridad del Rosario. Municipalidad de Rosario (1933), pp. 50-51 y 173.

18 Estas prerrogativas evidencian la debilidad de los sistemas reguladores en los inicios del sistema de salubridad. En redes de un solo punto de distribución como éstas, considerando precios equivalentes, a mayor distancia del nodo los costes aumentan y la rentabilidad decrece, lo que limita la competencia al área de menores costes y desalienta la inversión en los barrios (Foreman-Peck y Millward, 1994, pp. 41-47 y 60-61). Sobre las concesiones a las empresas de servicios en Rosario, Lanciotti (2005). 
cación de instalaciones había consolidado el predominio de empresas únicas dando lugar a la formación de monopolios naturales en el último tercio del siglo $\mathrm{XIX}^{19}$.

Considerando que el acceso a los servicios de aguas corrientes y cloacas determinaba las condiciones de la higiene urbana, la intervención estatal (mediante la gestión directa o la regulación) se dirigió a garantizar la amplia cobertura de este bien de utilidad pública, marcando una diferencia con los servicios de electricidad y telefonía, en principio orientados a un mercado más selectivo. Los efectos de la regulación fueron disímiles según la región y el período, pero bajo los sistemas de gestión indirecta y propiedad privada de los servicios, las concesionarias tendieron a abusar de su posición, condicionando las inversiones o fijando elevados precios que restringían el acceso al servicio por debajo del óptimo social ${ }^{20}$.

Las cláusulas orientadas a prever comportamientos oportunistas fueron manifiestamente imprecisas en el caso analizado. No se definían acciones a seguir cuando la calidad del servicio fuera deficiente; la reserva del derecho de fiscalización de la municipalidad no establecía mecanismos de control. Sólo se asignaba la supervisión de las obras a oficinas técnicas creadas ad hoc, que debían aprobar cada sección puesta en servicio, pero no se designaron responsables para la fiscalización del funcionamiento una vez finalizadas las obras. De modo que la función reguladora de la administración municipal se limitaba a la inspección de la construcción de las obras y a la fijación de una tarifa máxima en pesos oro $^{21}$.

Las compañías de aguas corrientes y de cloacas eran free standing companies: empresas jurídicamente autónomas, constituidas en Londres, para proveer los servicios de aguas corrientes y cloacas en Rosario. El término señala el contraste entre esta modalidad de inversión y la de las multinacionales, cuyas subsidiarias en el extranjero eran resultado de la extensión de actividades desarrolladas en el país de origen.

19 Millward (2005), pp. 41-54; Foreman-Peck y Millward (1994), pp. 9-13 y 41-47; Hassan (1985); Jacobson (2000), y Jacobson y Tarr (1999).

20 La diferencia con nuestro caso radica en la respuesta estatal. Tanto en Estados Unidos como en Inglaterra, la deficiente calidad del servicio y la lenta extensión de las redes durante la expansión urbana del siglo XIX impulsaron su municipalización. Hacia 1900, el 83 por 100 de los sistemas de agua potable de las principales ciudades británicas era de propiedad pública, y de propiedad municipal en el 82 por 100 de las ciudades norteamericanas. En ambos países, la inversión estatal superó con creces la inversión privada precedente, mejorando el alcance y calidad del servicio. En Francia, se desarrolló un modelo combinado de gestión privada con propiedad pública de los sistemas, evitándose los conflictos por la realización de inversiones comunes a los sistemas de gestión y propiedad privada. Hassan (1985) p. 539; Millward (2005), pp. 41 y ss.; Jacobson (2000), pp. 4-26; Jacobson y Tarr (1999).

21 La debilidad de la legislación reguladora fue común en todos los países cuando se instalaron los sistemas, y si bien los dispositivos se habían desarrollado, los procedimientos de control de calidad seguían siendo deficientes en 1900. Foreman-Peck y Millward (1994), pp. 44-47; Millward (2005), pp. 41-54. 
Los negocios en el exterior de las free standing companies no estaban asociados con actividades o empresas afincadas en el país donde tenían su sede, y en algunos casos estaban bajo el control de grupos de inversión con distintos grados de autonomía ${ }^{22}$.

El grupo Morrison era propietario de la mayoría del paquete accionario de las compañías de salubridad; además, sus directivos formaron parte de los directorios de River Plate Trust y de otras empresas ligadas al grupo. Entre 1890 y 1913, varios directores de RPTLA formaron parte de los consejos de administración de las compañías de aguas corrientes y de cloacas: A. J. FitzHugh, J. Anderson y P. Carr fueron sucesivamente directores de la compañía de cloacas; a su vez, J. Morris, C. J. Gunther, J. H. Duncan, R. Neild., T. Farrell, W. Wilson, F. Isaac y J. Anderson, integraron el consejo de la compañía de aguas corrientes ${ }^{23}$. Las empresas compartían además el personal administrativo y técnico. Gerente, subgerente, secretario, jefe de personal e ingeniero consultor, amén del personal de las oficinas técnica, de producción y administrativa, revistaban en las mismas oficinas en Rosario, aunque las empresas llevaran la contabilidad por separado. El cruce de consejeros y la asignación de tareas administrativas y técnicas a un único equipo de profesionales indicarían que no sólo la propiedad, sino también la gestión de las empresas, eran controladas por el grupo Morrison.

La comparación del capital social de ambas compañías indica que, al comienzo de sus actividades, el capital por acciones de la empresa de aguas era sensiblemente menor al de la empresa de cloacas, pero hacia finales del período los montos respectivos se habían equiparado (Cuadro 1). La divergencia resulta del mayor incremento del capital de la empresa de aguas: 162 por 100, frente al 53 por 100 de aumento del capital de la empresa de cloacas entre 1896 y 1930. Por el contrario, la cuantía de los debentures ${ }^{24}$ integrados por la empresa de cloacas superó ampliamente al de la compañía de aguas en ese período. La divergencia revela distintas modalidades de captación de capital de inversión y también el alza del endeudamiento de la empresa de cloacas con relación a sus recursos de capital (véase la columna 8 del Cuadro 1). Para evaluar esta cuestión, examinaremos las decisiones de emisión con respecto a la situación de la empresa en cada caso.

Según Wilkins (1988), las free standing companies fueron la forma típica de inversión directa británica en el exterior antes de 1914. Previamente el capital de estas empresas se computaba como inversión de cartera, es decir, sus acciones se estimaban como parte del capital gestionado por los grupos de inversión (Chapman, 1985). Acerca de los tipos de inversión británica en el exterior, véanse Jones (1995) y Jones (2000). El debate en torno a las free standing companies, en Wilkins y Schröter (1998). La incidencia de esta discusión en Argentina, en Regalsky (2002), pp. 115-120.

23 Jones (1973), pp. 307-310.

24 Los debentures son obligaciones no garantizadas por los activos de las empresas. La razón entre deuda y recursos propios (debt-to-equity) constituye un indicador de la solvencia de la empresa. Libby, Libby y Short (2005), pp. 512 y 514. 
CUADRO 1

CAPITAL DE LAS EMPRESAS DE AGUAS CORRIENTES Y CLOACAS DE ROSARIO, 1896-1930 (libras*)

\begin{tabular}{|c|c|c|c|c|c|c|c|c|}
\hline \multirow[b]{2}{*}{ Año } & \multicolumn{4}{|c|}{ Compañía de Aguas Corrientes } & \multicolumn{4}{|c|}{ Compañía de Obras de Salubridad } \\
\hline & Capital & Debentures & $\begin{array}{c}\text { Reservas/ } \\
\text { capital } \\
\text { social } \\
\text { (en \%) }\end{array}$ & $\begin{array}{l}\text { Deuda/ } \\
\text { recursos } \\
\text { propios }^{\star \star}\end{array}$ & Capital & Debentures & $\begin{array}{l}\text { Reservas/ } \\
\text { capital } \\
\text { social } \\
\text { (en \%) }\end{array}$ & $\begin{array}{c}\text { Deuda/ } \\
\text { recursos } \\
\text { propios }^{\star \star}\end{array}$ \\
\hline 1896 & 244.100 & 144.923 & & 0,59 & & & & \\
\hline 1897 & 244.100 & 180.000 & & 0,74 & & & & \\
\hline 1898 & 244.100 & 180.000 & 0,41 & 0,73 & 439.555 & 304.024 & & 0,69 \\
\hline 1899 & 244.100 & 195.000 & 0,82 & 0,79 & 517.030 & 338.684 & & 0,66 \\
\hline 1900 & 244.100 & 195.000 & 1,23 & 0,79 & 524.820 & 344.096 & & 0,66 \\
\hline 1901 & 244.100 & 195.000 & 1,64 & 0,79 & 526.625 & 345.350 & & 0,66 \\
\hline 1902 & 244.100 & 195.000 & 2,05 & 0,78 & 526.815 & 345.482 & & 0,66 \\
\hline 1903 & 244.100 & 195.000 & 2,46 & 0,78 & 526.815 & 345.482 & & 0,66 \\
\hline 1904 & 244.100 & 195.000 & 2,46 & 0,78 & 526.910 & 345.482 & & 0,66 \\
\hline 1905 & 244.100 & 193.000 & 2,75 & 0,77 & 527.860 & 346.208 & & 0,66 \\
\hline 1906 & 289.625 & 190.000 & 4,01 & 0,63 & 527.860 & 346.208 & & 0,66 \\
\hline 1907 & 290.000 & 190.000 & 5,52 & 0,62 & 527.860 & 435.222 & & 0,82 \\
\hline 1908 & 340.000 & 190.000 & 7,86 & 0,52 & 527.860 & 432.222 & & 0,82 \\
\hline 1909 & 364.192 & 190.000 & 7,60 & 0,48 & 528.810 & 432.053 & & 0,82 \\
\hline 1910 & 390.000 & 187.500 & 10,15 & 0,44 & 369.060 & 430.053 & & 1,17 \\
\hline 1911 & 440.000 & 184.583 & 14,79 & 0,37 & 369.200 & 428.220 & & 1,16 \\
\hline 1912 & 440.000 & 229.461 & 18,34 & 0,44 & 369.200 & 426.220 & 0,41 & 1,15 \\
\hline 1913 & 440.000 & 234.583 & 21,13 & 0,44 & 369.200 & 424.220 & 1,08 & 1,14 \\
\hline 1914 & 440.000 & 234.583 & 24,90 & 0,43 & 450.740 & 422.220 & 1,44 & 0,92 \\
\hline 1915 & 440.000 & 234.583 & 28,83 & 0,41 & 489.200 & 420.220 & 1,84 & 0,84 \\
\hline 1916 & 440.000 & 234.583 & 31,78 & 0,40 & 489.200 & 418.220 & 2,86 & 0,83 \\
\hline 1917 & 440.000 & 234.583 & 34,73 & 0,40 & 489.200 & 416.220 & 3,88 & 0,82 \\
\hline 1918 & 440.000 & 234.583 & 35,73 & 0,39 & 489.200 & 414.240 & 4,91 & 0,81 \\
\hline 1919 & 440.000 & 234.583 & 38,23 & 0,39 & 489.200 & 412.240 & 5,93 & 0,80 \\
\hline 1920 & 440.000 & 234.583 & 42,20 & 0,37 & 489.200 & 410.060 & 6,95 & 0,78 \\
\hline 1921 & 440.000 & 234.583 & 44,76 & 0,37 & 489.200 & 407.970 & 6,95 & 0,78 \\
\hline 1922 & 440.000 & 282.983 & 48,98 & 0,43 & 489.200 & 602.164 & 6,95 & 1,15 \\
\hline 1923 & 440.000 & 282.983 & 52,94 & 0,42 & 489.200 & 590.513 & 6,95 & 1,13 \\
\hline 1924 & 502.815 & 262.216 & 51,17 & 0,34 & 489.200 & 584.448 & 6,95 & 1,12 \\
\hline
\end{tabular}


CUADRO 1 (continuación)

CAPITAL DE LAS EMPRESAS DE AGUAS CORRIENTES Y CLOACAS DE ROSARIO, 1896-1930

(libras*)

\begin{tabular}{|c|c|c|c|c|c|c|c|c|}
\hline \multirow[b]{2}{*}{ Año } & \multicolumn{4}{|c|}{ Compañía de Aguas Corrientes } & \multicolumn{4}{|c|}{ Compañía de Obras de Salubridad } \\
\hline & Capital & Debentures & $\begin{array}{c}\text { Reservas/ } \\
\text { capital } \\
\text { social } \\
\text { (en \%) }\end{array}$ & $\begin{array}{l}\text { Deuda/ } \\
\text { recursos } \\
\text { propios }^{\star \star}\end{array}$ & Capital & Debentures & $\begin{array}{c}\text { Reservas/ } \\
\text { capital } \\
\text { social } \\
\text { (en \%) }\end{array}$ & $\begin{array}{l}\text { Deuda/ } \\
\text { recursos } \\
\text { propios }^{\star \star}\end{array}$ \\
\hline 1925 & 540.000 & 280.683 & 51,69 & 0,34 & 489.200 & 574.500 & 8,99 & 1,08 \\
\hline 1926 & 540.000 & 379.183 & 54,36 & 0,45 & 489.200 & 562.177 & 11,04 & 1,03 \\
\hline 1927 & 540.000 & 378.874 & 58,61 & 0,44 & 673.800 & 555.965 & 9,50 & 0,75 \\
\hline 1928 & 612.540 & 377.657 & 57,69 & 0,39 & 673.800 & 540.241 & 10,98 & 0,72 \\
\hline 1929 & 640.000 & 376.883 & 59,19 & 0,37 & 673.800 & 520.419 & 13,21 & 0,68 \\
\hline 1930 & 640.000 & 276.480 & 63,71 & 0,26 & 673.800 & 509.672 & 14,69 & 0,66 \\
\hline $\begin{array}{l}\text { * Para la } \\
\text { ** Razón } \\
\text { Fuentes: }\end{array}$ & $\begin{array}{l}\text { conversión } \\
\text { entre los deb } \\
\text { Municipalida } \\
\text { Consolidada }\end{array}$ & $\begin{array}{l}\text { de libras a pesc } \\
\text { oentures y el ca } \\
\text { ad de Rosario } \\
\text { de Aguas Corr }\end{array}$ & $\begin{array}{l}\text { os oro, Álvarez } \\
\text { pital más las } \\
\text { (1933), pp. } 49 \\
\text { ientes de Ros }\end{array}$ & $\begin{array}{l}\text { z (1929), pp. } 1 \\
\text { reservas. } \\
\text { 9-64, 93-94, } 1 \\
\text { sario (1935), p }\end{array}$ & $\begin{array}{l}06-108,130 \\
\text { o. } 91-97 \text {. }\end{array}$ & $-135,168-190$, & $217,226-227$ & lez (1976). \\
\hline
\end{tabular}

La red de aguas corrientes entró en servicio en 1887. Al principio, el número de usuarios creció lentamente y la crisis de 1890 complicó la captación de capitales para proseguir las obras, así que en 1896 se ajustó el capital y se reorganizó la empresa como Compañia Anónima Consolidada de Aguas Corrientes del Rosario, dando comienzo a una trayectoria estable ${ }^{25}$. La firma emitió acciones entre 1905 y 1911, y mantuvo su capital social hasta 1923, reiniciando entonces la emisión de acciones hasta 1929. Ésta se dirigió a financiar la extensión de la red y las ampliaciones del capital coincidieron estrictamente con las fases expansivas del ciclo económico, cuando el crecimiento del mercado potencial presuponía el aumento de la demanda (1906-1911 y 1924-1929). También se emitieron debentures al 4 por 100 de interés al comienzo de las operaciones, en 1912 y en 1926. En cada oportunidad, se utilizó este mecanismo para complementar la captación de capital por vía de la emisión de acciones.

La empresa de cloacas tuvo un desarrollo más accidentado, desencadenándose diversos problemas técnicos y financieros debido a la demora de la puesta en servicio 
por deficiencias constructivas del sistema. Hacia 1890, la empresa había finalizado la primera etapa de construcción de las cloacas; pero la inspección municipal determinó que las obras no cumplían con las especificaciones de la concesión respecto a calidad de los materiales y características técnicas de los caños, y negó la aprobación. Considerando las condiciones del mercado financiero londinense a comienzos del decenio de 1890, la interrupción de las obras y el inicio del conflicto en una coyuntura de crisis incidió profundamente en el devenir posterior de la empresa ${ }^{26}$. Hacia 1897, ésta se hallaba en una pésima situación financiera, no percibía ingresos y no pagaba intereses de los debentures desde 1891. Fue entonces cuando River Plate Trust asignó a James Anderson su reconstrucción financiera y la realización de un acuerdo con el municipio. La empresa fue refundada como Rosario Drainage Company Limited (Compañía de Obras de Salubridad del Rosario), con un capital nominal de 535.000 libras dividido en 107.000 acciones (27.000 ordinarias y 80.000 preferentes con un dividendo preferencial no acumulativo del 6 por 100 anual). El paquete de acciones continuaba en manos de los antiguos accionistas: RPTLA y James Anderson, entre otros 27 .

En 1899 se formalizó un nuevo convenio, con el compromiso de la empresa de corregir las deficiencias técnicas que motivaron el conflicto. El sistema se inició ese año. Al siguiente, se emitieron debentures por valor 100.000 libras al 4 por 100 para implantar las reformas acordadas con el municipio. La situación no mejoró demasiado. A los conflictos judiciales con éste se agregó el embargo de las rentas de la compañía por la demanda de un particular encargado de negociar la venta de la empresa a la Municipalidad de Rosario y, también, los reclamos por intereses atrasados de los tenedores de debentures al 5 por 100 de interés colocados en $1897^{28}$.

Durante la primera década de operaciones, la empresa no estuvo en condiciones de emitir unas acciones que difícilmente serían adquiridas ante la nula rentabilidad y los problemas financieros de la firma. La limitada expansión del servicio y el incumplimiento del plan de inversión pautado ahondaron los conflictos con el municipio, y los resultados de la explotación continuaron siendo negativos, impidiendo el pago del servicio de las obligaciones durante los primeros años del Novecientos ${ }^{29}$.

El oscuro panorama comenzó a cambiar en 1907. Ese año, la justicia provincial falló a favor de la compañía en el juicio contra el municipio por la cláusula de obli-

\footnotetext{
26 Sobre el conflicto entre municipalidad y firma, Municipalidad de Rosario (1895) y Lanciotti (2002).

27 No se dispone de la contabilidad de la primera compañía de cloacas, cuyo capital inicial se estima sobrevaluado. Según los cálculos de los peritos de la comisión fiscalizadora municipal, su valor real en el momento de la transferencia era de 208.094 libras. Municipalidad de Rosario (1933), pp. 173-175.

$28 \quad$ Municipalidad de Rosario (1933), pp. 178-181.

29 The Argentine Year's Book (1903), p. 441.
} 
gatoriedad de conexión a la red estipulada en el acuerdo de $1899^{30}$. Se renegoció entonces el pago de intereses con los tenedores de debentures y cuando los ingresos comenzaron a cubrir los costes fijos y los intereses, el consejo puso en marcha un plan de ajuste que incluía la reducción del capital. Según las memorias de la firma, el ajuste era parte de una estrategia para relanzar la colocación de acciones en el mercado. En concreto, esta operación formalizaba los acuerdos con accionistas y tenedores de debentures a partir de la flexibilización de las condiciones de ampliación del sistema de cloacas aprobadas por el municipio en 1910. En función del acuerdo, convenientemente publicitado en medios londinenses, el ajuste corregía la sobrevaloración del capital realizada en el momento de la transferencia de la compañía, habilitando la liquidación de dividendos para acciones ordinarias por primera vez (Cuadros 1 y 2$)^{31}$.

De acuerdo con lo previsto, en 1913 se emitieron 120.000 libras en acciones preferentes para financiar la ampliación de las obras convenida con el municipio, pero la amenaza del conflicto mundial obstaculizó la captación de capitales. Finalizada la guerra, el Consejo explicó a los accionistas que el cambio en el escenario financiero europeo había limitado la colocación de las acciones, debiéndose reinvertir mayores ingresos de lo previsto en 1913. La asamblea autorizó entonces la emisión de 250.000 libras en debentures al 7 por 100 de interés para sustituir las obligaciones previas. Se extendía así el plazo de financiación de la deuda a costa de intereses más altos.

Entre 1913 y 1927, no se amplió el capital accionarial y la construcción de las obras avanzó muy lentamente, siendo financiada con los ingresos corrientes. La expansión del sistema sobre la base de la reinversión de las utilidades dilató la constitución de la reserva mínima de capital hasta 1926, y mantuvo los dividendos de las acciones ordinarias en un escaso 3 por 100 hasta 1922, cuando ingresó nuevo capital de inversión por la integración de los debentures al 7 por 100 (Cuadros 1 y 2).

30 Este acuerdo establecía dicha obligatoriedad para las fincas comprendidas en el radio del servicio de cloacas. Pero una ordenanza del concejo deliberante declaró que la firma no tenía facultades para obligar a los vecinos a construir las cloacas domiciliarias; por ello, la empresa se querelló contra el municipio. En 1902, la justicia dictaminó que aquélla no podía obligar a los propietarios no conectados a pagar la tasa, pero también que la autoridad local debía exigir la conexión. La firma entabló un nuevo juicio por daños y perjuicios por el monto no percibido por tasa de drenaje. Finalmente, en 1907, la Corte de la provincia de Santa Fe falló a su favor. Municipalidad de Rosario (1933), pp. 177-181.

31 En la Ordenanza Municipal número 70 de 1910 se renegociaron las bases para la expansión del sistema de cloacas — antes fijadas en función del aumento de la población- en los siguientes términos: las inversiones estarían condicionadas al mantenimiento de las tarifas en pesos oro y la exclusión de futuras rebajas de las mismas, así como la exoneración de impuestos y la extensión de la concesión a setenta años (Lanciotti, 2005). "Las negociaciones para fijar todos los problemas pendientes con la municipalidad fueron resumidas en octubre de 1910 y se llegó a un acuerdo satisfactorio en diciembre de 1910", celebraba The Argentine Year's Book, poco después del acuerdo. The Argentine Year's Book (1912), p. 390. 
CUADRO 2

UTILIDADES DE LAS EMPRESAS DEL GRUPO MORRISON EN ROSARIO, 1898-1930

\begin{tabular}{|c|c|c|c|c|c|c|c|c|}
\hline \multirow[b]{2}{*}{ Año } & \multicolumn{4}{|c|}{ Compañía de Aguas Corrientes } & \multicolumn{4}{|c|}{ Compañía de Obras de Salubridad } \\
\hline & Libras & $\begin{array}{c}\text { Utilidades/ } \\
\text { capital } \\
\text { (en \%) }\end{array}$ & $\begin{array}{c}\text { Utilidades/ } \\
\text { capital + } \\
\text { reservas } \\
\text { (en \%) }\end{array}$ & $\begin{array}{l}\text { Divi- } \\
\text { dendos } \\
\text { (en \%) }\end{array}$ & Libras & $\begin{array}{c}\text { Utilidades/ } \\
\text { capital } \\
\text { (en \%) }\end{array}$ & $\begin{array}{c}\text { Utilidades/ } \\
\text { capital + } \\
\text { reservas } \\
\text { (en \%) }\end{array}$ & $\begin{array}{c}\text { Divi- } \\
\text { dendos } \\
\text { (en \%) }\end{array}$ \\
\hline 1896 & 5.187 & 2,12 & 2,12 & & & & & \\
\hline 1897 & 7.025 & 2,88 & 2,88 & & & & & \\
\hline 1898 & 11.199 & 4,59 & 4,57 & 1,5 & -8.793 & & & \\
\hline 1899 & 12.648 & 5,18 & 5,14 & 2,5 & -3.983 & & & \\
\hline 1900 & 15.615 & 6,40 & 6,32 & 3,5 & -5.826 & & & \\
\hline 1901 & 16.513 & 6,76 & 6,66 & 4,0 & -10.607 & & & \\
\hline 1902 & 16.098 & 6,59 & 6,46 & 3,5 & -8.577 & & & \\
\hline 1903 & 17.518 & 7,18 & 7,00 & 4,0 & -8.242 & & & \\
\hline 1904 & 20.842 & 8,54 & 8,33 & 5,0 & -6.307 & & & \\
\hline 1905 & 23.596 & 9,67 & 9,41 & 6,0 & -4.562 & & & \\
\hline 1906 & 29.167 & 10,07 & 9,68 & 7,0 & -9.330 & & & \\
\hline 1907 & 33.071 & 11,40 & 10,81 & 7,0 & 2.001 & 0,4 & 0,38 & \\
\hline 1908 & 37.640 & 11,07 & 10,26 & 7,0 & 2.870 & 0,5 & 0,54 & \\
\hline 1909 & 43.222 & 11,87 & 11,03 & 8,0 & 5.172 & 1,0 & 0,98 & \\
\hline 1910 & 50.561 & 12,96 & 11,77 & 18,0 & 9.086 & 2,5 & 2,46 & 1,5 \\
\hline 1911 & 53.792 & 12,23 & 10,65 & 8,0 & 16.970 & 4,6 & 4,60 & 3,0 \\
\hline 1912 & 55.007 & 12,50 & 10,56 & 8,0 & 18.648 & 5,1 & 5,03 & 4,0 \\
\hline 1913 & 63.647 & 14,47 & 11,94 & 8,0 & 23.235 & 6,3 & 6,23 & 4,0 \\
\hline 1914 & 63.699 & 14,48 & 11,59 & 8,0 & 26.047 & 5,8 & 5,70 & 3,0 \\
\hline 1915 & 62.417 & 14,19 & 11,01 & 8,0 & 30.477 & 6,2 & 6,12 & 3,0 \\
\hline 1916 & 60.715 & 13,80 & 10,47 & 8,0 & 31.044 & 6,3 & 6,17 & 3,0 \\
\hline 1917 & 60.545 & 13,76 & 10,21 & 8,0 & 34.508 & 7,1 & 6,79 & 3,0 \\
\hline 1918 & 53.859 & 12,24 & 9,02 & 8,0 & 37.178 & 7,6 & 7,24 & 3,0 \\
\hline 1919 & 65.322 & 14,85 & 10,74 & 8,0 & 40.422 & 8,3 & 7,80 & 3,0 \\
\hline 1920 & 70.481 & 16,02 & 11,26 & 8,0 & 45.498 & 9,3 & 8,70 & 3,0 \\
\hline 1921 & 59.918 & 13,62 & 9,41 & 8,0 & 46.542 & 9,5 & 8,90 & 3,0 \\
\hline 1922 & 75.763 & 17,22 & 11,56 & 8,0 & 37.929 & 7,8 & 7,25 & 3,0 \\
\hline 1923 & 75.140 & 17,08 & 11,17 & 8,0 & 41.792 & 8,5 & 7,99 & 5,0 \\
\hline 1924 & 84.803 & 16,87 & 11,16 & 8,0 & 38.146 & 7,8 & 7,29 & 5,0 \\
\hline 1925 & 101.674 & 18,83 & 12,41 & 8,0 & 54.022 & 11,0 & 10,13 & 6,0 \\
\hline
\end{tabular}


CUADRO 2 (continuación)

UTILIDADES DE LAS EMPRESAS DEL GRUPO MORRISON EN ROSARIO, 1898-1930

\begin{tabular}{|c|c|c|c|c|c|c|c|c|}
\hline \multirow[b]{2}{*}{ Año } & \multicolumn{4}{|c|}{ Compañía de Aguas Corrientes } & \multicolumn{4}{|c|}{ Compañía de Obras de Salubridad } \\
\hline & Libras & $\begin{array}{c}\text { Utilidades/ } \\
\text { capital } \\
\text { (en \%) }\end{array}$ & $\begin{array}{c}\text { Utilidades/ } \\
\text { capital + } \\
\text { reservas } \\
\text { (en \%) }\end{array}$ & $\begin{array}{c}\text { Divi- } \\
\text { dendos } \\
\text { (en \%) }\end{array}$ & Libras & $\begin{array}{c}\text { Utilidades/ } \\
\text { capital } \\
\text { (en \%) }\end{array}$ & $\begin{array}{c}\text { Utilidades/ } \\
\text { capital + } \\
\text { reservas } \\
\text { (en \%) }\end{array}$ & $\begin{array}{c}\text { Divi- } \\
\text { dendos } \\
\text { (en \%) }\end{array}$ \\
\hline 1926 & 92.512 & 17,13 & 11,10 & 8,0 & 71.939 & 14,7 & 13,24 & 7,0 \\
\hline 1927 & 108.947 & 20,18 & 12,72 & 8,0 & 78.439 & 11,6 & 10,63 & 7,5 \\
\hline 1928 & 96.875 & 15,82 & 10,03 & 8,0 & 86.249 & 12,8 & 11,53 & 8,0 \\
\hline 1929 & 103.389 & 16,15 & 10,15 & 8,0 & 97.049 & 14,4 & 12,72 & 8,0 \\
\hline 1930 & 84.390 & 13,19 & 8,05 & 8,0 & 90.024 & 13,4 & 11,65 & 8,0 \\
\hline
\end{tabular}

Fuentes: Municipalidad de Rosario (1933), pp. 111-112, 126-127, 130-135, 218, 224-7; Compañía Consolidada de Aguas Corrientes de Rosario (1935), pp. 91-97.

A partir de 1925, el incremento de los ingresos comenzó a aplicarse a la distribución de utilidades, permitiendo dividendos del 6 por 100 sobre el capital. Se convino entonces la extensión de la red de cloacas a los barrios, para lo cual se emitió una nueva serie de acciones ordinarias que fueron integradas en $1927^{32}$.

La proporción de las obligaciones sobre los recursos de capital de la empresa de cloacas señalan que la captación de capital externo para la construcción de las obras se efectuó principalmente mediante el endeudamiento por la vía de la emisión de debentures, siguiendo una modalidad inversa a la adoptada por la compañía de aguas corrientes. La emisión limitada de acciones acompañada de una mayor emisión de debentures fue una estrategia ocasionalmente utilizada por los grupos de inversión y las compañías holding de origen norteamericano y europeo para financiar la construcción de obras y servicios de infraestructura de elevado capital inicial. Este modo de captar recursos les permitía seguir controlando las empresas subsidiarias por mayoría de votos en asamblea y percibir el margen de beneficio adicional del capital que superara el interés de las obligaciones ${ }^{33}$. El mecanismo era adecuado para

32 Municipalidad de Rosario (1933), pp. 176-188.

33 Los grupos franceses utilizaron este mecanismo para financiar las inversiones ferroviarias en Argentina (Regalsky, 2002, pp. 293 y 338). Asimismo, las compañías holding de electricidad (American E Foreign Power, Electric Bond E Share y Société Financière de Transports et d'Entreprises Industrielles) financiaron parte de sus inversiones en América Latina (pero también en Estados Unidos) mediante la emisión de debentures, tal como puede verse en sus balances anuales. 
concesiones que no estipularan dividendos máximos sobre capital accionario porque éste se mantenía en un nivel mínimo. De modo que cabe preguntarse si lo identificado en la empresa de cloacas responde a una estrategia del grupo inversor o si, en realidad, constituyó la única alternativa posible frente a los problemas técnicos y financieros experimentados por la compañía.

Las ampliaciones del capital accionarial de la empresa de cloacas se habían producido en 1914 y en 1927, con cierto retraso respecto a las fases expansivas del ciclo económico y después de que el aumento de los ingresos permitiera cubrir el pago de los intereses por las obligaciones y distribuir mínimos dividendos. La difícil colocación de acciones de una empresa poco rentable en períodos de retracción de los mercados de capitales dilató la realización de inversiones y contribuyó a aumentar los costes financieros. En el ámbito de negocios británico se responsabilizaba de la situación a las autoridades municipales, pero lo cierto es que, con la puesta en vigencia de la obligatoriedad de las conexiones en 1907, los ingresos de la compañía de cloacas no garantizaban dividendos similares a los distribuidos por otras empresas del grupo Morrison (Gráfico 1). Los dividendos de esta firma fueron siempre inferiores, salvo de 1925 a 1930, cuando se situaron, en promedio, entre el 6 y el 8 por $100^{34}$.

El aplazamiento de las inversiones mantuvo al sistema operando al límite de su capacidad. Las oportunidades para incrementar los ingresos y utilidades se vieron restringidas por el desajuste entre el momento de inversión de la empresa y el ciclo económico. Sólo al final de las fases ascendentes del ciclo, cuando el aumento de las entradas habilitaba dividendos mínimos, la compañía podía captar capitales de inversión para expandir la red. En las fases de crecimiento económico, la insuficiente capacidad instalada representada en una red de cloacas poco extendida condicionaba el incremento de ingresos; mientras que en las coyunturas recesivas se aumentaba la capacidad instalada, a la par que una elevada porción de los ingresos se aplicaba al pago del servicio de las obligaciones. Considerando además que la emisión de debentures escoltaba los sucesivos intentos de colocar acciones en el mercado, esta modalidad parece haber constituido la única opción que permitía prescindir del empleo de fondos propios en coyunturas desfavorables.

Por cierto, la situación de la empresa de aguas era otra. Especialmente a partir de 1905, los ingresos crecientes y la rentabilidad sostenida dieron amplio margen para financiar la extensión de la red de agua potable mediante la reinversión de utilidades, evitando un endeudamiento con altos costes financieros. La satisfactoria situación económico-financiera de la firma y el aumento del mercado durante el acelerado crecimiento demográfico de los años veinte posibilitaron financiar las ampliaciones de la red mediante la emisión de acciones y debentures. El incremento de las 


\section{GRÁFICO 1}

INGRESOS ANUALES DE LAS EMPRESAS DE AGUAS CORRIENTES Y CLOACAS DE ROSARIO, 1896-1930

(en pesos oro sellado)

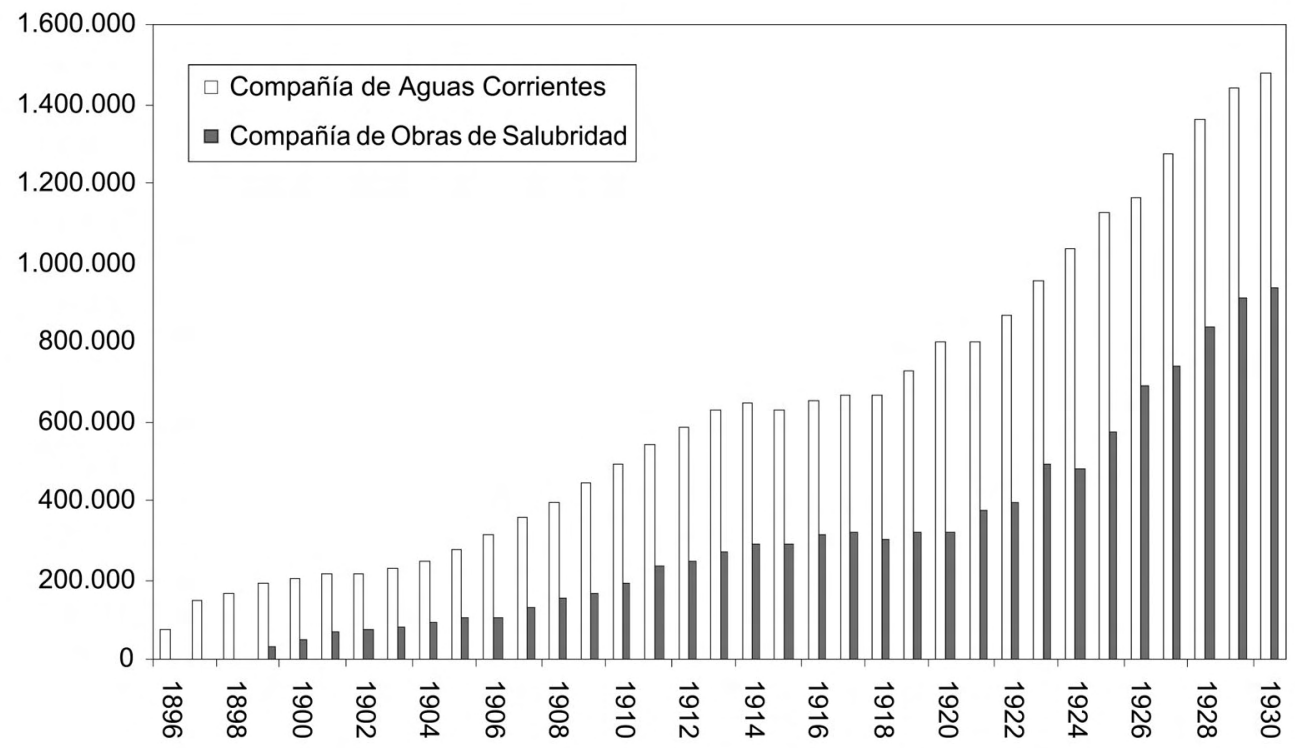

Fuentes: Municipalidad de Rosario (1933), pp. 115-116, 136-140, 220-221; Compañía Consolidada de Aguas Corrientes de Rosario (1935), pp. 91-97.

utilidades se destinó al pago de dividendos a los accionistas hasta un máximo del 8 por 100, aplicándose el remanente al incremento de las reservas de capital ${ }^{35}$.

Descontando el pago de los impuestos británicos sobre renta y ganancias, las utilidades no distribuidas se transferían a la cuenta de reservas. El monto asignado a esta cuenta superaba el 2 por 100 de las utilidades líquidas anuales fijado por el Código de Comercio argentino y el 5 por 100 establecido por la legislación europea.

35 En 1910, se pagaron dividendos del 18 por 100 para compensar a los accionistas por la retribución inferior al promedio recibida en los primeros años. Como no disponemos de la cotización de las acciones para calcular el rendimiento de los dividendos en relación al precio de mercado por acción, se evalúa la rentabilidad en el rendimiento sobre el capital propio (utilidades sobre capital y sobre capital más reservas) y en los dividendos distribuidos. Sobre los indicadores de la rentabilidad, véase Libby, Libby y Short (2005), pp. 705-707. Se considera que tasas de utilidad mayores del 10 por 100 son elevadas, tomando en cuenta que en Inglaterra la tasa de retorno promedio en las empresas del sector fue del 7,15 por 100 para el período anterior a la difusión de la municipalización del servicio. Foreman-Peck y Millward (1994), p. 33. 
Hacia 1930, las reservas acumuladas de la empresa de aguas alcanzaban el 64 por 100 del capital, excediendo ampliamente los mínimos de 10 y 20 por 100 sobre capital fijados por la legislación comercial argentina y europea, respectivamente ${ }^{36}$.

Por otra parte, la decisión de ampliar la capacidad de la red nunca se anticipó a la expansión de la demanda del servicio. La demora en la realización de inversiones frente al rápido incremento de la población coincidía con el criterio común de las empresas privadas de aguas corrientes, según el cual era más rentable no proveer del servicio a todos los clientes potenciales. La estrategia de postergar la satisfacción de la demanda marginal buscaba mantener la proporción de gastos operativos sobre los ingresos en su mínimo hasta tanto no se efectuaran inversiones de capital adicionales. Al mantener bajos costes operativos, se maximizaban los ingresos aplicados al servicio de las obligaciones colocadas, pago de dividendos y reinversión de utilidades, lo cual estimulaba el alza del precio de las acciones en el mercado de valores ${ }^{37}$.

Por cierto, estas decisiones no pueden ser interpretadas fuera de las condiciones de producción y los límites tecnológicos de la industria del agua. En contraste con los sistemas de gas, electricidad y telefonía, cuyo desarrollo tecnológico determinaba el incremento de los beneficios por rendimientos crecientes de escala, la tecnología aplicada a los sistemas de aguas corrientes y cloacas se mantuvo prácticamente sin cambios durante la primera mitad del siglo XX. Innovaciones como la utilización de bombas y motores a vapor, las cañerías de hierro y el desarrollo de sistemas de presión constante se habían puesto a punto en el siglo XIX, difundiéndose luego la aplicación de materiales y técnicas constructivas ya probadas. Además, la instalación subterránea de caños de suministro y desagüe era relativamente más costosa que el cableado eléctrico, y la expansión de las redes implicaba el aumento de los costes unitarios. En la medida en que no se desarrollaran nuevos sistemas de almacenamiento y distribución, la industria del agua no se beneficiaría de las economías de escala; de modo que las empresas no realizaron mayores inversiones en la infraestructura física que las exigidas por las autoridades reguladoras en cada caso ${ }^{38}$.

En este contexto, las estrategias financieras y de inversión de la Compañia de Aguas Corrientes del Rosario no sólo se tradujeron en un alto grado de capitalización, sino también en coeficientes de explotación suficientemente bajos (menores del 50 por 100) acorde al criterio de los inversores. El coeficiente de explotación de la empresa de aguas corrientes fue inferior al 50 por 100 hasta 1927, salvo en los años

\footnotetext{
36 Compañía Consolidada de Aguas Corrientes de Rosario (1935), pp. 82-83. Las reservas de las empresas de servicios públicos constituían generalmente el 10 por 100 del capital social en este período.

37 Sobre las pautas de inversión en las empresas de aguas corrientes, véanse Hassan (1985), pp. 544-545, y Jacobson (2000), pp. 48-57.

38 Sobre los cambios tecnológicos en la industria del agua, véanse Millward (2005), pp. 41 y 52; y Hassan (1995), pp. 189-193.
} 


\section{CUADRO 3}

COEFICIENTE DE EXPLOTACIÓN* DE LAS EMPRESAS DEL GRUPO MORRISON EN ROSARIO, 1896-1930

\begin{tabular}{lccccc}
\hline Años & $\begin{array}{c}\text { Compañía } \\
\text { de Aguas } \\
\text { Corrientes }\end{array}$ & $\begin{array}{c}\text { Compañía } \\
\text { de Obras de } \\
\text { Salubridad }\end{array}$ & Años & $\begin{array}{c}\text { Compañía } \\
\text { de Aguas } \\
\text { Corrientes }\end{array}$ & $\begin{array}{c}\text { Compañía } \\
\text { de Obras de } \\
\text { Salubridad }\end{array}$ \\
\hline $\mathbf{1 8 9 6}$ & 43,97 & & $\mathbf{1 9 1 4}$ & 39,18 & 23,00 \\
$\mathbf{1 8 9 7}$ & 48,80 & & $\mathbf{1 9 1 5}$ & 39,73 & 16,95 \\
$\mathbf{1 8 9 8}$ & 43,83 & & $\mathbf{1 9 1 6}$ & 45,00 & 22,48 \\
$\mathbf{1 8 9 9}$ & 43,44 & 124,15 & $\mathbf{1 9 1 7}$ & 45,99 & 21,50 \\
$\mathbf{1 9 0 0}$ & 41,17 & 69,23 & $\mathbf{1 9 1 8}$ & 51,03 & 22,22 \\
$\mathbf{1 9 0 1}$ & 42,44 & 59,59 & $\mathbf{1 9 1 9}$ & 47,62 & 22,05 \\
$\mathbf{1 9 0 2}$ & 43,54 & 49,19 & $\mathbf{1 9 2 0}$ & 49,45 & 20,84 \\
$\mathbf{1 9 0 3}$ & 42,96 & 49,58 & $\mathbf{1 9 2 1}$ & 52,49 & 21,63 \\
$\mathbf{1 9 0 4}$ & 41,39 & 42,61 & $\mathbf{1 9 2 2}$ & 48,07 & 22,76 \\
$\mathbf{1 9 0 5}$ & 42,32 & 41,67 & $\mathbf{1 9 2 3}$ & 48,08 & 21,87 \\
$\mathbf{1 9 0 6}$ & 40,42 & 41,50 & $\mathbf{1 9 2 4}$ & 46,95 & 24,31 \\
$\mathbf{1 9 0 7}$ & 41,90 & 36,61 & $\mathbf{1 9 2 5}$ & 47,15 & 21,46 \\
$\mathbf{1 9 0 8}$ & 42,04 & 31,81 & $\mathbf{1 9 2 6}$ & 47,45 & 21,66 \\
$\mathbf{1 9 0 9}$ & 41,46 & 30,70 & $\mathbf{1 9 2 7}$ & 47,75 & 22,20 \\
$\mathbf{1 9 1 0}$ & 41,53 & 28,85 & $\mathbf{1 9 2 8}$ & 57,54 & 28,62 \\
$\mathbf{1 9 1 1}$ & 43,56 & 25,72 & $\mathbf{1 9 2 9}$ & 57,11 & 27,77 \\
$\mathbf{1 9 1 2}$ & 40,61 & 26,55 & $\mathbf{1 9 3 0}$ & 54,92 & 28,82 \\
$\mathbf{1 9 1 3}$ & 39,62 & 23,66 & & & \\
\hline
\end{tabular}

* Suma de los gastos de explotación y de los gastos administrativos sobre los ingresos.

Fuentes: Municipalidad de Rosario (1933), pp. 116-120 y 221-224.

1918 y 1921, cuando el encarecimiento del combustible elevó los gastos (Cuadro 3). El incremento observable en los últimos años no representa un aumento real de los gastos, sino una operación contable correctiva del costo de las instalaciones: la amortización financiera de instalaciones y accesorios comenzó a ser incluida en la cuenta de gastos de explotación desde $1928^{39}$.

39 Los gastos de explotación comprendían egresos por tratamiento y distribución del agua, como esterilización del la misma y conservación y renovación de máquinas, depósitos, cañerías, servicios domiciliarios, medidores, filtros, edificios, tanques y muebles. Municipalidad de Rosario (1933), pp. 81-82, 121 y ss. Se considera que coeficientes menores del 50 por 100 representan decisiones operativas eficientes, aunque el rango varía según la industria, siendo más elevados en transporte y electricidad. Entre 1900 y 1915, el coeficiente de la empresa de aguas fue más alto que el de Obras Sanitarias de la Nación (OSN) en Buenos Aires. En la década siguiente, OSN aumentó sus gastos de explotación (con un coeficiente de 50,9 en 1915-1919, y de 62,2 en 1920-1924) y los gastos de la empresa inglesa bajaron. En las provincias, OSN fue deficitaria hasta 1925. Regalsky y Salerno (2006), p. 18. 
Durante los primeros quince años de operaciones, el coeficiente de explotación de la empresa de aguas promediaba el 43 por 100. La mejora en el funcionamiento de las máquinas de bombeo y filtrado alentó su baja entre 1912 y 1915, seguida de un alza moderada de los gastos operativos desde 1916, que se debió al incremento de los gastos de distribución de agua por la instalación de medidores. Cuando aumentaron los ingresos producidos por este servicio en reemplazo de los servicios de renta fija, el coeficiente se estabilizó nuevamente. Como la colocación de medidores era atributo de la compañía, el servicio medido se aplicó en las unidades de gran consumo (entre ellas, los inquilinatos), y se mantuvo el servicio de renta fija en las fincas de alto valor locativo y menor consumo de agua. La conversión produjo la disminución del suministro promedio de agua a la par que el aumento de los ingresos por servicios con medidor, cuyo precio medio por metro cúbico era mayor al precio medio de los servicios a renta fija ${ }^{40}$.

El coeficiente de explotación de la firma de cloacas, inicialmente muy alto por la falta de ingresos, descendió notoriamente apenas se puso en funcionamiento el sistema, siendo en tres años menor del 50 por 100. La tendencia decreciente continuó hasta llegar a un mínimo del 17 por 100 en 1915. Ello estuvo vinculado a la exigua inversión en obras tras la instalación de la red en el área central. No se hicieron obras para extender la cobertura inicial, al menos hasta 1912, de modo que en los primeros quince años de operaciones, los gastos de explotación se ciñeron a reparaciones mínimas y a la conservación y limpieza de cloacas y bocas de tormentas. Luego, la gradual extensión de la red fue financiada con los ingresos corrientes, que se duplicaron entre 1910 y 1922; por tanto, el alza de las entradas mantuvo el coeficiente de explotación en un nivel inferior al de otras empresas de servicios públicos. Hacia finales de los veinte, la inclusión de la amortización financiera en la cuenta de gastos de explotación explica el aumento del coeficiente, que aún así no era mayor del 30 por 100.

La reducida proporción sobre el total de los gastos de explotación de la firma de cloacas tuvo como contrapartida el alto porcentaje de gastos financieros, sobre todo entre 1901 y 1912, cuando rondaba el 70 por 100 del total de ingresos (Cuadro 4). Ello respondía a los mecanismos de captación del capital de inversión antes citados. La renegociación y emisión de nuevos debentures a mayor interés elevó notablemente los costes financieros. En contraste, la composición de los gastos de la empresa de aguas muestra una disminución acentuada de los gastos financieros que confirmaría la relación entre la mayor disponibilidad de recursos propios y la favorable evolución económica de la compañía en el nuevo siglo.

$40 \quad$ Entre 1920 y 1930, el número de servicios con medidores aumentó de 3.055 a 31.171, y los servicios a renta fija disminuyeron de 23.337 a 22.551. El aumento del número de servicios fue del 28 por 100, mayor que el del volumen de agua suministrada por la difusión del consumo medido. Municipalidad de Rosario (1933), pp. 157-158. 


\section{CUADRO 4}

COMPOSICIÓN DE LOS GASTOS

(porcentajes sobre los egresos totales)

\begin{tabular}{|c|c|c|c|c|c|c|}
\hline \multirow[b]{2}{*}{ Años } & \multicolumn{3}{|c|}{ Compañía de Aguas Corrientes } & \multicolumn{3}{|c|}{ Compañía de Obras de Salubridad } \\
\hline & $\begin{array}{l}\text { Gastos de } \\
\text { producción }\end{array}$ & $\begin{array}{c}\text { Gastos de } \\
\text { administración }\end{array}$ & $\begin{array}{l}\text { Gastos } \\
\text { financieros }\end{array}$ & $\begin{array}{l}\text { Gastos de } \\
\text { producción }\end{array}$ & $\begin{array}{c}\text { Gastos de } \\
\text { administración }\end{array}$ & $\begin{array}{c}\text { Gastos } \\
\text { financieros }\end{array}$ \\
\hline 1896 & 33 & 34 & 33 & & & \\
\hline 1897 & 33 & 32 & 35 & & & \\
\hline 1898 & 31 & 33 & 36 & 25 & 63 & 12 \\
\hline 1899 & 33 & 33 & 34 & 20 & 56 & 24 \\
\hline 1900 & 33 & 34 & 33 & 14 & 30 & 56 \\
\hline 1901 & 35 & 34 & 31 & 7 & 26 & 67 \\
\hline 1902 & 35 & 35 & 30 & 8 & 24 & 69 \\
\hline 1903 & 34 & 36 & 29 & 10 & 23 & 67 \\
\hline 1904 & 36 & 36 & 28 & 10 & 22 & 68 \\
\hline 1905 & 37 & 37 & 26 & 9 & 25 & 66 \\
\hline 1906 & 40 & 36 & 24 & 9 & 20 & 72 \\
\hline 1907 & 44 & 35 & 21 & 12 & 28 & 60 \\
\hline 1908 & 45 & 36 & 19 & 11 & 24 & 65 \\
\hline 1909 & 46 & 37 & 18 & 12 & 24 & 64 \\
\hline 1910 & 44 & 40 & 16 & 12 & 26 & 62 \\
\hline 1911 & 47 & 39 & 14 & 12 & 28 & 60 \\
\hline 1912 & 45 & 34 & 20 & 13 & 30 & 57 \\
\hline 1913 & 46 & 33 & 21 & 12 & 30 & 58 \\
\hline 1914 & 45 & 33 & 22 & 11 & 32 & 57 \\
\hline 1915 & 45 & 33 & 22 & 11 & 25 & 64 \\
\hline 1916 & 53 & 30 & 17 & 11 & 33 & 56 \\
\hline 1917 & 49 & 35 & 17 & 11 & 32 & 56 \\
\hline 1918 & 52 & 33 & 15 & 12 & 34 & 54 \\
\hline 1919 & 54 & 31 & 15 & 12 & 36 & 53 \\
\hline 1920 & 56 & 31 & 13 & 12 & 35 & 53 \\
\hline 1921 & 53 & 30 & 17 & 12 & 35 & 53 \\
\hline 1922 & 51 & 32 & 16 & 9 & 31 & 59 \\
\hline 1923 & 46 & 35 & 19 & 10 & 27 & 63 \\
\hline 1924 & 47 & 34 & 20 & 11 & 27 & 62 \\
\hline 1925 & 50 & 35 & 15 & 9 & 30 & 61 \\
\hline 1926 & 46 & 32 & 22 & 11 & 33 & 56 \\
\hline 1927 & 49 & 33 & 18 & 11 & 36 & 52 \\
\hline 1928 & 56 & 32 & 12 & 29 & 31 & 40 \\
\hline 1929 & 58 & 29 & 13 & 28 & 33 & 40 \\
\hline 1930 & 51 & 25 & 24 & 27 & 29 & 44 \\
\hline
\end{tabular}

Fuentes: Municipalidad de Rosario (1933), pp. 116-120 y 221-224. 
La empresa de aguas corrientes no obtuvo utilidades significativas hasta que se libraron a servicio las obras de cloacas. En principio, podría inferirse que la demora en la construcción de la red de éstas en el momento en que las autoridades locales cambiaban su perspectiva sobre las empresas británicas produjo un aumento relativo de los costes de oportunidad de la empresa de aguas corrientes, al obstaculizar la integración entre ambos sistemas. Pero antes de explicar el lento incremento de los ingresos de la empresa de aguas hasta 1905, señalaremos algunas características de la demanda del servicio durante esos años.

El suministro de agua corriente constituía un problema prioritario para el gobierno municipal, preocupado por mejorar la higiene pública, pero el agua potable no era un bien necesario según la perspectiva de amplios sectores de la población. Cuando se otorgaron las concesiones, el funcionamiento de la red de agua corriente era una exigencia de la élite comercial e industrial urbana, alertada por los riesgos de incendio e informada de los patrones higienistas. Pero, pudiendo obtener el agua por bombeo manual sin costo alguno, para los sectores de menores ingresos la conexión a la red de agua corriente era una imposición municipal más que un beneficio público.

En este sentido debe interpretarse la modificación del convenio de aguas corrientes que, en 1888, estipuló la obligatoriedad de conexión para los usuarios situados en el área de cobertura de cloacas. La cláusula, incluida normalmente en las concesiones de este tipo, permitía a las empresas ampliar su mercado por vía administrativa y no por vía económica, como garantía de la elevada inversión inicial en la realización de las obras. Autorizaba, además, a que la empresa arbitrara la modalidad bajo la cual imponer la conexión a los usuarios, evitando el enfrentamiento directo entre éstos y el gobierno local.

Dado que los servicios de aguas corrientes y cloacas atendían mayoritariamente una demanda residencial (a diferencia de los servicios de gas y electricidad, más orientados al comercio y la industria) y que la demanda de agua potable había sido impulsada por iniciativa estatal, es claro que la suspensión de las obras de cloacas incidió negativamente sobre los ingresos de la empresa de aguas, al postergar la activación de la cláusula de obligatoriedad de conexión a la red de agua potable en función del vínculo con el sistema de cloacas fijado en la modificación de 1888.

Cuando dicho sistema fue puesto en servicio, los ingresos y las utilidades de la Compañía de Aguas Corrientes del Rosario iniciaron su ascenso. Las utilidades anuales en pesos oro se quintuplicaron entre 1899 y 1930. La tasa de utilidades sobre recursos propios se mantuvo en torno al 10 por 100 desde 1905, porcentaje que fue en aumento a partir de 1907, hasta alcanzar un máximo del 20 por 100 en 1927. Los dividendos se equiparaban a los distribuidos por las rentables sociedades hipotecarias 
del grupo Morrison en Argentina y al rendimiento promedio de las inversiones británicas de cartera en el exterior antes de la I Guerra Mundial ${ }^{41}$.

En consecuencia, es posible concluir que la integración de los servicios de aguas corrientes y cloacas en un único sistema de salubridad constituía un elemento central en la rentabilidad de las inversiones del grupo, aunque este objetivo no se realizara en el plazo previsto. Esto implica que el desigual desempeño de estas compañías no puede interpretarse fuera del marco de las decisiones del grupo Morrison, aun cuando el análisis de sus trayectorias sea clave para evaluar el desarrollo de las inversiones del grupo.

La evolución de las utilidades no revela posibles efectos negativos de la I Guerra Mundial sobre estas compañías. La empresa de aguas corrientes no registró aumentos sustanciales de sus costes operativos, salvo en los años 1918 y 1921, por el encarecimiento del carbón utilizado como combustible. Los gastos de explotación crecieron moderadamente entre 1916 y 1921 porque las inversiones en obras se habían desarrollado en la fase anterior, el insumo básico era abundante y de fácil extracción, y no se requería de materia prima importada. Después de 1922, las utilidades netas reiniciaron su ascenso. Por su parte, las utilidades de la empresa de cloacas se incrementaron a partir de la ampliación de la red en 1910. Durante la guerra, los ingresos y la tasa de utilidad se mantuvieron estables, aunque inferiores entre el 6 y el 8 por 100 a los de la empresa de aguas. Luego, la tasa aumentó nuevamente, alcanzando un máximo del 13 por 100 sobre el capital empleado en 1926.

Que las utilidades no se vieran afectadas por el incremento de los costes operativos durante la I Guerra Mundial, como sucedió en otras empresas de servicios (especialmente, tranviarias o de electricidad), puede atribuirse a la débil dependencia de recursos energéticos del tipo de servicio analizado. Otros efectos, como la inflación de posguerra, las fluctuaciones del tipo de cambio por la suspensión del patrón oro y el posterior retorno de la libra a la paridad de 1914, incidieron más específicamente en las compañías extranjeras de salubridad. Sin embargo, estos factores no alteraron la rentabilidad de las empresas analizadas debido a una particular condición estipulada en los contratos, que no registra antecedentes en las concesiones otorgadas en otras ciudades americanas o europeas. Tal condición era la fijación de tarifas en pesos oro sellado ${ }^{42}$.

\footnotetext{
41 Sobre la rentabilidad de las inversiones británicas en ese período, Pollard (1985), p. 496.

42 En Argentina, las tarifas de servicios urbanos fueron generalmente fijadas en moneda nacional convertible a pesos oro, requiriendo habitualmente los aumentos la aprobación de los concejos municipales o de los gobiernos provinciales, según el caso. En Río de Janeiro, el veto del intendente impidió el aumento de las tarifas de tranvías, electricidad y telefonía (a cargo de empresas extranjeras) en las décadas de 1920 y 1930 (Boone, 1995, pp. 361-363). Las tarifas de los servicios públicos en Estados Unidos tenían similares restricciones, aunque las comisiones reguladoras estatales autorizaron el aumento de las tarifas en los años veinte.
} 
En los años de la posguerra, las empresas de servicios públicos cuyas tarifas habían sido fijadas en monedas locales, reclamaron ajustes de éstas que contemplaran la inflación de precios y el aumento de costes operativos. La rentabilidad de las empresas extranjeras disminuyó cuando dicho aumento no cubrió el de los gastos y cuando percibieron sus ingresos en monedas subvaluadas. Pero la fijación de las tarifas en pesos oro sostuvo el incremento de los ingresos de las empresas del grupo Morrison por ajuste automático a dicha paridad, favoreciéndolas especialmente la subida del oro acaecida entre 1919 y 1925. La devaluación de la libra con relación al oro, el aumento del número de servicios y el alza de los alquileres base sobre los que se calculaba la tarifa de los servicios de renta fija, garantizaron utilidades crecientes en libras y en pesos oro. Esta situación culminaría en la crisis de los años treinta, cuando el abandono del patrón oro, la implantación de tipos de cambio diferenciales y la restricción de la salida de divisas extranjeras, ocasionaron la depreciación de los activos en libras, el aumento de los costes por diferencia en los tipos de cambio y la caída de los ingresos de la explotación.

\section{Observaciones finales}

Las trayectorias de la Compañía de Aguas Corrientes del Rosario y la Compañía de Obras de Salubridad muestran que los resultados económicos de las empresas británicas en el exterior, particularmente en Argentina, no dependieron de factores unívocos como las características del mercado, la creación de estructuras organizativas inadecuadas, la vulnerabilidad de las empresas frente a las autoridades locales o la posición anglófoba de las élites tras la crisis de 1890. La gestión de las inversiones, las estrategias financieras y productivas, el acceso a la información por parte de los directivos del grupo y de las autoridades, los efectos de las economías a escala, la capacidad de expansión de las redes con relación a los incentivos provistos por la tecnología, las características del mercado y los dispositivos reguladores incidieron en el desempeño de las empresas de servicios públicos del grupo Morrison en Argentina. En lo que respecta a los resultados satisfactorios de la empresa de aguas, se establece que fueron producto de las estrategias y competencias desarrolladas bajo la coordinación del grupo inversor, cuyas decisiones operativas y financieras, orientadas a eludir el riesgo y a asegurar el mercado, se revelaron exitosas frente a los cambios y fluctuaciones económicas, al menos hasta 1930.

La prestación de servicios urbanos de infraestructura conlleva una fuerte inversión en activos específicos que sólo pueden ser utilizados en la localización prevista, sin posibilidad de ser movilizados ni reconvertidos para otras actividades. De modo que la "vulnerabilidad" de las empresas y su escaso poder de negociación, derivado 
de la fuerte inversión fija en activos específicos, no constituye una particularidad de las empresas británicas, sino una característica de las empresas de servicios públicos, cualquiera sea el origen de su capital. Pero esta condición estaba prevista en los contratos de concesión, que compensaban la alta inversión inmovilizada por las empresas con la extensión de concesiones a largo plazo en condiciones monopolistas, y por la inclusión de cláusulas de conexión obligatoria que aseguraban la creación de un mercado por la vía administrativa. El otorgamiento de concesiones por setenta años bajo condiciones de exclusividad y la obligatoriedad de las conexiones para los usuarios incluidos en el área de cobertura del sistema acordadas con las empresas del grupo Morrison relativizaron los factores de riesgo e incertidumbre que podrían haber afectado a sus inversiones en activos fijos.

La prioridad de construir las redes de servicios en una ciudad de intenso crecimiento demográfico y la incapacidad financiera del gobierno local para emprender la inversión en el momento en que se contrataron las obras, debilitaron el poder de negociación de éste. Ello se observa en la inclusión de cláusulas de incentivo a la inversión, ciertamente excepcionales en cuanto a concesiones de este tipo (como el ajuste automático de tarifas), o en la flexibilización de los objetivos de inversión inicialmente acordados con las firmas. Cuando la empresa de cloacas asumió la reconstrucción de las obras en las que había utilizado materiales de inferior calidad a la acordada, comenzó a presionar por modificaciones en los convenios para postergar la extensión de las redes. Al cabo de un arduo proceso de conflicto y negociación entre las partes, las demandas empresariales fueron incorporadas a los contratos reguladores, lo cual manifiesta la significativa capacidad de presión ejercida por la compañía.

De modo que la relación con las autoridades locales, señalada por Charles Jones como una de las causas que explican la retirada de los inversores ingleses de las compañías de servicios públicos en Argentina, no parece operar como un factor determinante de la inestabilidad de las mismas, sino más bien como el resultado de las estrategias financieras y los criterios de inversión del grupo británico que operaba en el sector. De hecho, la experiencia de la empresa de aguas corrientes muestra que las firmas británicas que cumplieron con las inversiones acordadas mantuvieron un bajo nivel de conflictividad con las autoridades locales, al menos hasta la crisis de los años treinta ${ }^{43}$.

43 No hubo mayores controversias entre el gobierno y la empresa de aguas corrientes sobre la calidad y volumen de agua antes de 1930. Entre 1920 y 1930, la provisión había aumentado de 96 a 123 litros de agua diarios por habitante, volumen equivalente al promedio en los municipios europeos, y al 65 por 100 de lo provisto en los municipios estadounidenses. La situación cambió en 1930, cuando comenzaron los debates sobre la regulación tarifaria. 
Los primeros conflictos entre el gobierno municipal y la Compañía de Obras de Salubridad del Rosario fueron consecuencia del incumplimiento de los contratos de concesión en lo referente a calidad y extensión del servicio. Al respecto, la compañía fiduciaria del grupo Morrison, River Plate Trust, tuvo mayores dificultades para gestionar el capital de la inversión inicial por circunstancias coyunturales vinculadas a la emergencia de la crisis de 1890. En este proceso, la autoridad reguladora se fortaleció circunstancialmente por la crisis, que afectaba a la capacidad financiera de la empresa de cloacas. Como resultado, las controversias entre partes elevaron los costes de transacción por los procesos judiciales y la renegociación de los contratos. Obstaculizaron, además, la captación de nuevos capitales en el mercado, provocando el aumento de los costes financieros de la empresa y el agravamiento general de su situación económica y financiera. El insuficiente capital aplicado a la construcción de la red de cloacas limitó la capacidad productiva del sistema, que requería una importante inversión para cubrir los altos costes de instalación de caños y desagües. La ausencia de innovaciones tecnológicas consolidó las restricciones de la oferta derivadas de la subinversión, configurando un mercado poco flexible con escaso aprovechamiento de las economías de escala.

Estos factores, que explicarían los resultados poco satisfactorios de la empresa de cloacas, no se aplican a la Compañía de Aguas Corrientes, cuyos ingresos estables, rentabilidad creciente y utilidades superiores al promedio evidencian las amplias posibilidades de desarrollo que tenían las empresas de servicios públicos en las ciudades argentinas de gran expansión demográfica durante el período. La trayectoria de esta firma muestra que las inversiones británicas en servicios públicos podían ser muy rentables después de la I Guerra Mundial, aun considerando una inversión moderada de capital y limitadas innovaciones productivas. La adecuación parcial y paulatina de la inversión a los cambios del mercado, así como la decisión de explotar un servicio de alta calidad y elevados precios sobre la base de recursos locales abundantes y poco costosos, produjeron el nivel elevado de beneficios de esta empresa. Ello favoreció la mayor autonomía de sus recursos respecto al mercado financiero.

En las urbes de intensa expansión demográfica fueron frecuentes los conflictos por la extensión de las redes, la calidad y los precios del servicio, ya que la formación de monopolios naturales alentó comportamientos oportunistas, agravados por la carencia de dispositivos específicos de control del volumen y calidad del agua suministrada. En todos los casos, la escasa inversión realizada por las empresas privadas de salubridad fue el factor desencadenante de los conflictos con las autoridades. Políticas de inversión manifiestamente conservadoras fueron adoptadas por empresas de aguas corrientes tanto en las ciudades americanas como en las europeas. 
La modalidad de desarrollo tecnológico de estos servicios convalidó un conjunto de saberes y prácticas institucionalizadas que las firmas proveedoras reproducían en distintos contextos. Entre las empresas británicas, el comportamiento escasamente innovador observado en el sector se vio reforzado por cierta suspicacia sobre las posibilidades de expansión del mercado por vías no administrativas, así como por el imperativo de declarar resultados positivos a los accionistas, verificables en bajos coeficientes de explotación y altas reservas, en el marco de estrategias de inversión dirigidas a maximizar las ganancias financieras de los grupos que las controlaban.

La evolución del capital accionarial y del coeficiente de explotación de la Compañía de Aguas Corrientes del Rosario muestra una inversión gradual y limitada, además de escasa innovación tecnológica y aversión al riesgo. El examen de las empresas inglesas aquí consideradas corrobora lo señalado por Wilkins acerca de la orientación predominante de la inversión británica externa hacia servicios públicos e industrias de baja tecnología gestionados por compañías autónomas, en contraste con los sectores de alta tecnología liderados por las firmas alemanas. La observación coincide, además, con lo señalado por Geoffrey Jones en cuanto a los mecanismos alternativos de control de las empresas por parte de los directivos del grupo y la tendencia a operar en entornos de negociación, evitando la competencia.

El desarrollo de firmas de mayor tecnología no atrajo a las free standing companies en la medida en que las decisiones operativas y financieras de estas empresas eran definidas en el espacio del consejo directivo de los grupos británicos. En esta dirección, las decisiones de inversión en proyectos productivos eran alentadas por las expectativas de obtener ganancias financieras en el mercado londinense. De modo que la evaluación de la rentabilidad de las inversiones incluía no sólo crecientes beneficios de explotación, sino también bajos coeficientes de explotación y un elevado nivel de reservas acumuladas, como variables factibles de promover el alza en el precio de las acciones.

Los accionistas mayoritarios de las firmas administradas por River Plate Trust eran al mismo tiempo accionistas de otras empresas del grupo. Asimismo, los miembros de los respectivos consejos configuraban un elenco estable que alternativamente estaba a cargo de la gestión de una u otra empresa. Como directivos de RPTLA, tanto John Morris como James Anderson desplegaron estrategias de inversión orientadas a minimizar los riesgos mediante la diversificación de proyectos y la búsqueda de socios para aprovechar las emergentes oportunidades de inversión. La aplicación de una lógica equivalente a la gestión de las empresas minimizó la inversión de capital en un sector cuyo desarrollo involucraba altas inversiones en activos fijos y específicos, una vez asegurado el control del mercado por los contratos de concesión.

Las trayectorias divergentes no resultaron, además, de modalidades distintas de gestión empresarial, sino del fallo en la aplicación de las estrategias del grupo Morri- 
son en la gestión de la empresa de cloacas: las secuelas no previstas de la subinversión en el sistema de cloacas frente al cambio en la coyuntura económica a partir de la crisis de 1890 incidieron negativa y persistentemente en la trayectoria de la firma.

La coordinación de las decisiones de gestión de las compañías según las estrategias formuladas con miras a la rentabilidad de las inversiones del grupo, se manifestó de varias formas. En primer lugar, destacó la continuidad de equipos directivos comunes y la conformación de una única plantilla administrativa y técnica. Como ha señalado Leff, en estos casos la estructura del grupo inversor favorecía economías de escala en la utilización de recursos gerenciales y técnicos escasos, situación especialmente aplicable a los grupos que operaban en países de América Latina. Asimismo, la extensa trayectoria de los negocios del grupo en la región concentró conocimientos específicos sobre las características y fluctuaciones de los mercados rioplatenses en manos del grupo directivo. Ambos elementos representaron una ventaja competitiva para las empresas del grupo Morrison, ventaja que contribuye a explicar su desempeño en los términos planteados por Geoffrey Jones.

Además, la gestión de los servicios de aguas corrientes y cloacas tendía a conformar un sistema integrado a partir del establecimiento de condiciones de contratación que aseguraban un mercado único para ambas firmas, a fin de eliminar riesgos y minimizar costes de transacción, como quedó representado en las cláusulas de obligatoriedad de las conexiones y en la provisión del insumo básico de la empresa de cloacas a un precio subsidiado por la empresa de aguas. La integración de ambos sistemas era razón suficiente para mantener la empresa de cloacas bajo el control del grupo, pese a que su rentabilidad no fuera aceptable. Aun operando por debajo de su capacidad, la puesta en marcha del sistema de cloacas garantizaba el funcionamiento del de aguas corrientes que sostenía la rentabilidad de las inversiones en Rosario.

Por cierto, los cambios de la economía mundial entre finales del siglo XIX y la crisis de los años treinta aumentaron la imprevisión y la incertidumbre, factores que, según Geoffrey Jones, también incidieron negativamente en el devenir económico de las firmas británicas. No obstante, en los casos analizados la inclusión de cláusulas tarifarias para contrarrestar la inflación revela la anticipada evaluación de los directivos sobre los factores que podían elevar los riesgos y afectar los ingresos corrientes de las empresas del grupo Morrison. Esta evaluación fue un factor clave del crecimiento de los ingresos y de las utilidades de las mismas durante la década de 1920.

La información disponible para los miembros de los consejos de las empresas del grupo Morrison era más precisa y completa que la manejada por los funcionarios municipales, tal como puede identificarse en la resolución de los conflictos entre las partes. Durante el siglo XIX, los servicios de salubridad se habían desarrollado en Inglaterra bajo un modelo de gestión descentralizada, donde eran habituales los con- 
flictos y las negociaciones entre autoridades locales y empresas. El conjunto de prácticas tanto jurídicas como operativas resultantes de este proceso formaba parte del conocimiento de los directivos de las empresas británicas. Dicho conocimiento fue utilizado para anticipar los riesgos e incertidumbres específicamente asociados a este tipo de proyectos, impulsando la formalización de dispositivos y mecanismos tendentes a reducir los efectos de las fluctuaciones institucionales y económicas sobre la rentabilidad de las empresas. Al mismo tiempo, las asimetrías de información limitaron el efecto de las inversiones sobre la utilidad social del sistema, por cuanto el municipio no sólo no logró impedir los aumentos de tarifas, sino que tuvo que renegociar los planes de inversión estipulados en la concesión original.

\section{Bibliografía}

ÁLVAREZ, Juan (1929): Temas de historia económica argentina, Buenos Aires, El Ateneo. Anuario Pillado de la deuda pública y sociedades anónimas establecidas en la República Argentina (1899), Buenos Aires, Imprenta de la Nación.

BARBERO, María Inés (1990): "Grupos empresarios, intercambio comercial e inversiones italianas en la Argentina. El caso de Pirelli (1910-1920)", Estudios Migratorios Latinoamericanos, 5, 15-16, pp. 267-340.

BOONE, Christopher (1995): "Streetcar and Politics in Rio de Janeiro: Private Enterprise versus Municipal Government in the Provision of Mass Transit, 19031920", Journal of Latin American Studies, 27, 2, pp. 343-365.

CHANDLER, Alfred Jr. (1996): Escala y diversificación. La dinámica del capitalismo industrial, Zaragoza, Prensas Universitarias de Zaragoza, 2 vols.

CHAPMAN, Stanley (1985): "British-Based Investment Groups before 1914", Economic History Review, 38, 2, pp. 230-251.

COMPAÑÍA CONSOLIDADA DE AGUAS CORRIENTES DE ROSARIO (1935): Conflicto por rebaja de tarifas entre la Municipalidad y la Cía. de Aguas Corrientes de Rosario. Contestación al Informe Municipal de la Comisión Municipal Fiscalizadora, Rosario.

FOREMAN-PECK, James, y MILLWARD, Robert (1994): Public and private ownership of British industry, 1820-1990, Oxford-New York, Clarendon Press-Oxford University Press.

GARCÍA HERAS, Raúl (1994): Transporte, negocios y política. La Compañía Anglo Argentina de Tranvías. 1876-1981, Buenos Aires, Sudamericana.

HANNAH, Leslie (1991): "Scale and Scope: Towards a European Visible Hand", Business History, 33, 2, pp. 297-309. 
HASSAN, John (1985): "The Growth and Impact of the British Water Industry in the Nineteenth Century", Economic History Review, 38, 4, pp. 531-548.

-(1995): “The water industry 1900-1951; a failure of public policy?", en MILLWARD, Robert, y SINGLETON, John (eds.), The Political Economy of Nationalization in Britain, 1920-1950, Cambridge, Cambridge University Press, pp. 189-211. JACOBSON, Charles (2000): Ties that bind. Economic and Political Dilemmas of Urban Utilities Networks, 1800-1990, Pittsburg, University of Pittsburg Press.

JACOBSON, Charles, y TARR, Joel (1999): “Ownership and Financing of Infrastructure: Historical Perspectives", Policy Research Working Paper Series: 1466, Washington, The World Bank.

JONES, Charles (1973): British Financial Institutions in Argentina, 1860-1914, Tesis Doctoral inédita, University of Cambridge.

-(1992): El Reino Unido y América: Inversiones e influencia económica, Madrid, MAPFRE.

-(1995): “Los antecedentes de la moderna corporación transnacional: los grupos de inversión británicos en América Latina", en MARICHAL, Carlos (comp.), Las inversiones extranjeras en América Latina, 1850-1930, México, Fondo de Cultura Económica.

JONES, Charles; JONES, Linda, y GREENHILL, Robert (1977): “Public Utility Companies", en PLATT, Desmond C. M. (ed.), Business Imperialism 1840-1930. An inquiry based on British experience in Latin America, Oxford, Oxford University Press, pp. 77-118.

JONES, Geoffrey (1986): “The Performance of British Multinational Enterprise, 18901945", en HERTNER, Peter, y JONES, Geoffrey (eds.), Multinationals: Theory and History, Aldershot, Gower, pp. 96-112.

-(2000): Merchants to Multinationals. British Trading Companies in the Nineteenth and Twentieth Centuries, Oxford-New York, Oxford University Press.

LANCIOTTI, Norma S. (2002): "Las relaciones entre gobierno municipal y empresas de servicios públicos en Argentina: un estudio de caso, Rosario 1887-1910", Anuario de Espacios Urbanos 2002, pp. 98-116.

-(2005): “Conflictos y prácticas institucionales en la configuración de la política municipal de servicios públicos. Rosario (Argentina), 1890-1930", Segundas Jornadas de Historia Regional Comparada, Pontificia Universidad Católica de Río Grande do Sul, Porto Alegre (Brasil), 3-6 octubre [edición digital].

LEFF, Nathaniel (1978): "Industrial Organization and Entrepreneurship in Developing Countries: The Economic Groups", Economic Development and Cultural Change, 26, 4, pp. 661-675.

LIBBY, Robert; LIBBY, Patricia A., y SHORT, Daniel G. (2004): Financial accounting, Boston, Mass., McGraw-Hill/Irwin. 
LLUCH, Andrea, y SÁNCHEZ, Laura (2002): De movimiento popular a empresa. El cooperativismo eléctrico en La Pampa (1925-1950), Santa Rosa de la Pampa, Fondo Editorial Pampeano.

MILLER, Rory (1998): "British Free-Standing Companies on the West Coast of South America", en WILKINS, Mira, y SCHRÖTER, Harm (eds.), The Free-Standing Company in the World Economy, 1830-1996, New York, Oxford University Press, pp. 218-252.

MILLWARD, Robert (2005): Private and public enterprise in Europe: energy, telecommunications and transport, 1830-1990, Cambridge-New York, Cambridge University Press.

MUNICIPALIDAD DE ROSARIO (1895): Antecedentes relativos a la Obras de Cloacas y Desagües de esta Ciudad, Rosario, Librería y Papelería Italo-Suiza.

-(1933): Informe de la Comisión Municipal Fiscalizadora de las Compañias Consolidada de Aguas Corrientes del Rosario y Obras de Salubridad de Rosario, Rosario, Tipografía Llordén.

PLATT, Desmond C. M. (1977): Business Imperialism 1840-1930. An inquiry based on British experience in Latin America, Oxford, Oxford University Press.

POLLARD, Sidney (1985): “Capital exports, 1870-1914: ¿Harmful or beneficial?", Economic History Review, 38, 4, pp. 489-514.

REGALSKY, Andrés (2002): Mercados, Inversores y Elites. Las inversiones francesas en la Argentina, 1880-1914, Buenos Aires, Editorial de la Universidad de Tres de Febrero.

REGALSKY, Andrés, y SALERNO, Elena (2006): “En los comienzos de la empresa pública argentina. Una aproximación a dos casos: la Administración de los Ferrocarriles del Estado y las Obras Sanitarias de la Nación antes de 1930", XIV International Economic History Congress, Helsinki, 21-25 agosto.

REPUBLICA ARGENTINA. OBRAS SANITARIAS DE LA NACIÓN (1935): Obras Sanitarias de la Nación Reseña General Histórica Descriptiva y Estadística, Buenos Aires, Ministerio de Obras Públicas.

SOLVEIRA, Beatriz (2005): "Relación Estado-Empresas de Electricidad en la provincia de Córdoba durante la primera mitad del siglo XX", Seminario/Taller sobre empresas, CEEED-FCE-UBA, 13-14 junio.

The Argentine Year's Book, varios años, Londres-Buenos Aires, Wh. Smith \& Son, Robert Grant \& Co.

TORNQUIST, Ernesto (1920): El desarrollo económico de la República Argentina en los últimos cincuenta años, Buenos Aires.

VÁZQUEZ PRESEDO, Vicente (1976): Estadísticas históricas argentinas, 2 vols. Buenos Aires, Macchi.

WILKINS, Mira (1986): “Defining a firm: History and Theory”, en HERTNER, Peter, 
y JONES, Geoffrey (eds.), Multinationals: Theory and History, Aldershot, Gower, pp. 80-94.

-(1988): "The free-standing company, 1870-1914: an important type of British foreign direct investment", Economic History Review, 41, 2, pp. 259-282.

WILKINS, Mira, y SCHRÖTER, Harm (eds.) (1998): The Free-Standing Company in the World Economy, 1830-1996, New York, Oxford University Press. 